\title{
Cortical NAA Deficits in HIV Infection without Dementia: Influence of Alcoholism Comorbidity
}

\author{
Adolf Pfefferbaum*, ${ }^{*, 2}$, Elfar Adalsteinsson ${ }^{3,4}$ and Edith V Sullivan ${ }^{2}$ \\ 'Neuroscience Program, SRI International, Menlo Park, CA, USA; ${ }^{2}$ Department of Psychiatry and Behavioral Sciences, Stanford University School of \\ Medicine, Stanford, CA, USA; ${ }^{3}$ Department of Electrical Engineering and Computer Science, MIT, Cambridge, MA, USA; ${ }^{4}$ Harvard-MIT Division of \\ Health Sciences and Technology, MIT, Cambridge, MA, USA
}

\begin{abstract}
Alcoholism comorbidity is highly prevalent in individuals infected with human immunodeficiency virus (HIV). Each condition is known to affect brain structure, function, and metabolism, but the combined effects on the brain have only recently been considered. Single-voxel, proton MR spectroscopy (MRS) has yielded sensitive measures of early brain deterioration in the progression of HIV, but has limited coverage of neocortex, whereas MRS imaging (MRSI) can simultaneously interrogate large regions of cortex. Included were I 5 men with $\mathrm{HIV}+$ alcoholism, nine men with HIV alone, eight men with alcoholism alone (abstinent for 3-17 months), and 23 controls. The two HIV groups were matched in T-cell count and were not demented; the two alcoholism groups were relatively matched in lifetime alcohol consumption. We used MRSI with a variable-density spiral sequence to quantify major proton metabolites - N-acetylaspartate (NAA), creatine $(\mathrm{Cr}$ ), and choline (Cho) - in the superior parietal-occipital cortex. Metabolites were expressed in absolute units and as the NAA/Cr ratio. Significant group effects were present for NAA and $\mathrm{Cr}$. Only the HIV + alcoholism group was significantly affected, exhibiting a 0.8 SD deficit in NAA and a I.0 SD deficit in Cr. The deficits were not related to highly active antiretroviral therapy (HAART) status. Neither HIV infection nor alcoholism independently resulted in parietal-occipital cortical metabolite abnormalities, yet each disease carried a liability that put affected individuals at a heightened risk of neuronal compromise when the diseases were compounded. Further, the use of absolute measures revealed deficits in NAA and $\mathrm{Cr}$ that would have gone undetected if these metabolites were expressed as a ratio.

Neuropsychopharmacology (2005) 30, 1392-1399, advance online publication, 6 April 2005; doi: I 0. I038/sj.npp. I 300723
\end{abstract}

Keywords: alcoholism; HIV; spectroscopy; NAA; creatine; HAART

\section{INTRODUCTION}

Alcoholism comorbidity is highly prevalent in individuals infected with human immunodeficiency virus (HIV). It has been estimated that nearly half of those infected with HIV are also alcohol abusers or dependents (Lefevre et al, 1995). Alcohol can exacerbate HIV infection by acting as an immunosuppressant and interfering with potential positive effects of antiretroviral therapy (Wang and Watson, 1995). A primate study directly addressing this interaction revealed that Rhesus monkeys which were pretreated with high doses of alcohol and then infected with the simian version of HIV (SIV) showed a 64-fold greater presence of the virus than sucrose-exposed and SIV-infected controls (Bagby et al, 2003). In addition to general systemic effects,

*Correspondence: Dr A Pfefferbaum, Neuroscience Program, SRI International, 333 Ravenswood Avenue, Menlo Park, CA 94025, USA, Tel: + I 650859 2927, Fax: + I 650859 2743,

E-mail: dolf@synapse.sri.com

Received 22 November 2004; revised 8 February 2005; accepted 14 February 2005

Online publication: 17 February 2005 at http://www.acnp.org/citations/ NPP02 $1705040547 /$ default.pdf each condition is known to affect brain structure, function, and metabolism, but the combined effects on the brain are poorly understood and examined irregularly (eg Fein $e t$ al, 1995; Green et al, 2004; Heaton et al, 1995; Meyerhoff, 2001).

Single-voxel, proton MR spectroscopy (MRS) has proved to be a more sensitive, noninvasive index of early brain deterioration in the progression of HIV than conventional, structural MRI (Barker et al, 1995; Chang et al, 2002; Fuller et al, 2004; Meyerhoff, 2001; Moller et al, 1999b; Viondury et al, 1994). Early in the disease, basal ganglia are affected and show evidence of gliosis (abnormally high myoinositol/ creatine (Cr) levels) and possible signs of cell membrane activity (abnormally high choline/Cr levels), whereas in later stages marked by AIDS-dementia neuronal integrity, indexed by the $\mathrm{N}$-acetylaspartate/creatine ratio (NAA/Cr), shows signs of compromise, especially in frontal cortex, subjacent white matter, and basal ganglia (for reviews see Chang et al, 2002; Meyerhoff, 2001; Pfefferbaum et al, 2002). In addition, HIV infection interacts with age, resulting in an exacerbated increase in glial markers in frontal white matter and decrease in the neuronal marker in basal ganglia in older HIV-infected individuals (Ernst and Chang, 2004). 
The mainstay of MRS studies is based on the single-voxel approach focused on the basal ganglia and frontal cortex and white matter. Further, metabolite levels are typically expressed as ratios of $\mathrm{Cr}$, with the assumption that $\mathrm{Cr}$ fluctuates little with aging or disease. Although this approach has contributed significantly to the identification of potential targets of HIV infection and progression, it has two principal limitations: voxel size is too large (commonly $6 \mathrm{~cm}^{3}$; Lee et al, 2003) to target selective regions of fully volumed neocortex, and the assumption that $\mathrm{Cr}$ is stable regardless of age or disease can be questioned ( $\mathrm{Li}$ et al, 2003; Pfefferbaum et al, 1999b). Indeed, recent studies that have quantified metabolites as concentrations of the tissue fraction in the measured voxel provide evidence for increased $\mathrm{Cr}$ related to age (Li et al, 2003; Pfefferbaum et al, 1999b), disease (eg Alzheimer's disease: Pfefferbaum et al, 1999a; HIV-age interaction: Ernst and Chang, 2004), and have identified the $\mathrm{Cr}$ denominator as a significant source of metabolite measurement error relative to estimates based on absolute metabolite values corrected for tissue fraction (Li et al, 2003).

Here, we used MRSI with a variable-density spiral sequence to quantify major proton metabolites, NAA, Cr, and Cho, in the superior parietal-occipital cortex. This cortical region is difficult to image in the single-voxel mode, can be encompassed with the multiple small voxels $\left(1.1 \mathrm{~cm}^{3}\right)$ used in the MRS volumetric imaging mode, and may be a site of early pathology in cases of HIV-alcoholism comorbidity, given the known frontoparietal circuitry that can be disrupted in either disease (for reviews see Pfefferbaum et al, 2002; Sullivan, 2003). In addition, the measured metabolites were expressed in absolute units rather than ratios, an approach that could increase the sensitivity of the NAA measure if both NAA and $\mathrm{Cr}$ were low in a disease state (cf Chang et al, 2002).

\section{METHODS}

\section{Subjects}

The four subject groups comprised 23 healthy controls (18 men, five women), nine men with HIV infection (HIV), 15 men with HIV infection plus alcohol dependence $(n=14)$ or abuse $(n=1)(\mathrm{H}+\mathrm{A})$, and eight men with alcohol dependence alone (ALC). When studied, six men (67\%) with HIV alone were taking highly active antiretroviral therapy (HAART), and 10 men $(67 \%)$ in the $\mathrm{H}+\mathrm{A}$ group were taking HAART. All subjects gave written informed consent for participation. The controls were recruited from the local community by flyers, advertisement, and word of mouth; in addition, nine laboratory members volunteered for study as controls. The alcoholic subjects were recruited from local treatment programs. The HIV-infected subjects were recruited and screened through the AIDS Community Research Consortium by clinical research registered nurses or physicians. Only HIV subjects who received a Karnofsky score of at least 70 out of a maximum of $100(70=$ cares for self, able to live at home, unable to work; $100=$ normal, no complaints, no evidence of disease) (Karnofsky, 1949) and a $\mathrm{CD} 4$ count of at least 100 cells $/ \mathrm{mm}^{3}$ were included for study. Subjects in the four groups, except the nine laboratory members, underwent a formal interview with clinical research psychologists, who used the Structured Clinical Interview for the Diagnostic and Statistical Manual IV (American Psychiatric Association, 1994), and were excluded for Axis I diagnoses of Bipolar Disorder or Schizophrenia or for any nonalcohol substance use (except cannabis) in the previous month or abuse in the previous 3 months. Additional exclusion criteria for all subjects were history of head trauma with neurological symptoms, seizure disorder (unrelated to alcohol withdrawal), alcohol-related withdrawal symptoms at the time of study, CNS opportunistic infection, chemotherapy for malignancy, or active tuberculosis. Current nonalcohol substance dependence was an exclusionary criterion for all groups, but because of the high prevalence of substance abuse in patients with these diagnoses, we included subjects with past history $(>3$ months) of nonalcohol substance abuse or dependence. Although the patient groups could have a past history ( $>3$ months) of nonalcohol drug dependence, the past history of all but one man in the $\mathrm{H}+\mathrm{A}$ group was greater than 1 year; the one exception was dependent 7 months prior to study. In the $\mathrm{H}$ group, four men had past history of nonalcohol substance dependence and one had abuse, that is, $55 \%$; in the $\mathrm{H}+\mathrm{A}$ group, 12 men had past history of nonalcohol substance dependence and two had abuse, that is, $90 \%$; and in the alcohol-only group, one man had past history of nonalcohol substance dependence.

The four groups were matched in age. The two HIV groups were matched in CD4 count, Karnofsky score (a measure of clinical well-being), and the Peabody Picture Vocabulary Test (a culture-free test of general intelligence). No HIV subject received a Karnofsky score below 80 $(80=$ normal activity with effort, some signs, or symptoms of disease), and none was clinically demented. The two alcoholism groups consumed significantly more alcohol in their lifetime than did the nonalcoholic groups, but the alcoholism-alone group reported a higher total lifetime alcohol consumption than did the $\mathrm{H}+\mathrm{A}$ group. The alcoholism alone group had been abstinent from alcohol for 91-536 days (means $\pm S D=216.7 \pm 162.0$ ), and the $\mathrm{H}+\mathrm{A}$ group was alcohol abstinent for $1-1288$ days (means \pm $\mathrm{SD}=194.2 \pm 380.0$ ). Of the $14 \mathrm{H}+\mathrm{A}$ subjects, 10 had drunk alcohol 1-14 days prior to scanning; the remaining four had abstained from drinking for 7-43 months. At the start of each test session, subjects were given a breathalyzer test; subjects not achieving a score of 0.0 were not tested that day. Table 1 presents descriptive data for the four subject groups.

\section{MRSI Acquisition and Processing}

A General Electric $1.5 \mathrm{~T}$ Signa scanner with a standard quadrature head coil was used for acquisition of structural and spectroscopic imaging data. Structural imaging included a dual-echo, fast spin-echo (FSE) acquisition with a slice thickness of $3.5 \mathrm{~mm}$, contiguously sampling the entire brain (all subjects except the nine laboratory controls) or 32 slices (only the nine laboratory controls). The FSE acquisition was prescribed parallel to the AC-PC orientation, with a superior-inferior center $35 \mathrm{~mm}$ superior to the midpoint between the AC and PC. The centers of the anterior-posterior and left-right axes were in the geometric center of the field of view. Imaging parameters were as 
Table I Subject Characteristics (Mean \pm SD)

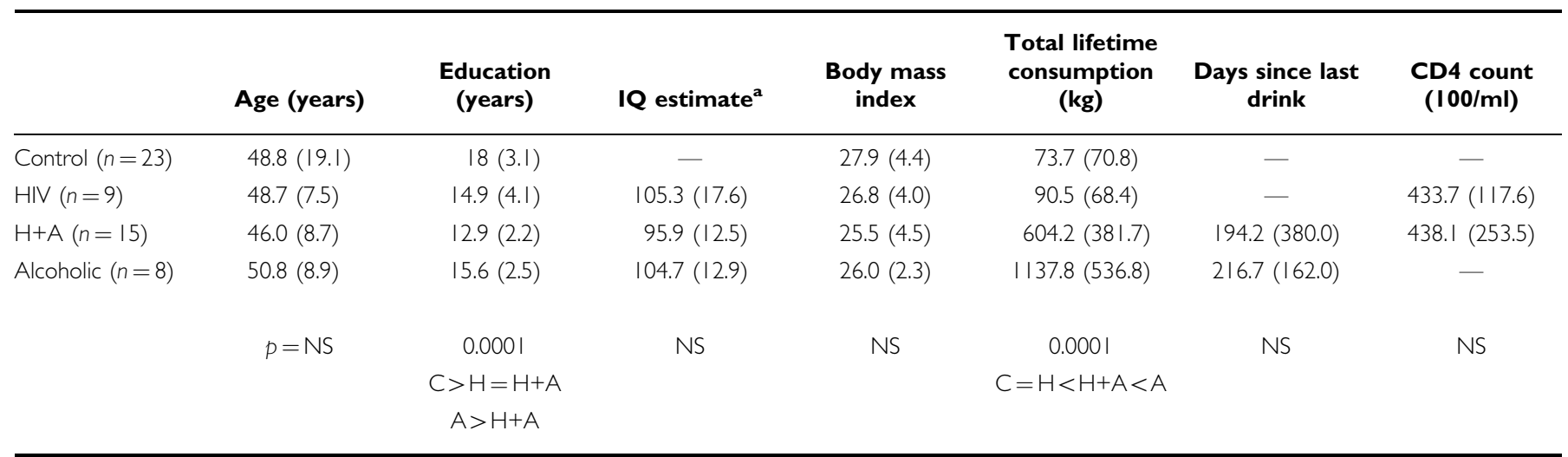

NS = not significant.

antelligence quotient (IQ) estimate for the three patient groups was based on the Peabody Picture Vocabulary Test.

follows: echo-train length $=8$; echo times $(\mathrm{TE} 1 / \mathrm{TE} 2)=50$ / $102 \mathrm{~ms}$; acquisition matrix $=256 \times 192$; single average, readout bandwidth $=15.625 \mathrm{kHz}$; and repetition time $(\mathrm{TR})=5500 \mathrm{~ms}$ (young subjects from our laboratory) and $7800 \mathrm{~ms}$ (all other subjects).

Prior to spectroscopic imaging, shims were optimized over the supratentorial brain by automated adjustment of the three linear and five nonlinear shim terms available on the scanner (Kim et al, 2002). Variable-density spiral acquisition was used to resolve chemical shift at $\mathrm{TE}=$ $144 \mathrm{~ms}$. Inversion recovery with $\mathrm{TI}=170 \mathrm{~ms}$ was applied to minimize lipid signals from subcutaneous fat. Metabolites were excited by a pair of minimum-phase spectral-spatial spin-echo pulses; the pass band included chemical shift for $\mathrm{NAA}, \mathrm{Cr}$, and Cho, while leaving the water resonance in the spectral stop band. The spatial profile excited an approximately $5.5 \mathrm{~cm}$ thick slab.

The readout was designed for a variable-density spiral sampling with a 36-pixel sampling diameter in $\left(k_{x}, k_{y}\right)$, and 32 phase encodes in $k_{\mathrm{z}}$. The voxel size was $1.1 \mathrm{~cm}^{3}$, and the acquisition time for metabolites was 15:20 min with a repetition period of $\mathrm{TR}=2 \mathrm{~s}$ (Adalsteinsson et al, 1999). A separate acquisition of unsuppressed water signal at a reduced $\mathrm{TR}=1200 \mathrm{~ms}$ provided high-SNR phase and frequency reference. The duration of the readout period for the current spectroscopic imaging protocol was limited to $232 \mathrm{~ms}$. For acquisition of long-T2 metabolites (such as NAA, Cr, and Cho) in regions of good main field homogeneity, this readout duration is relatively short and may thus limit spectral resolution and introduce spectral truncation artifacts.

Both the metabolite and water reference data sets were gridded onto a Cartesian $64 \times 64 \times 32 \times 128$ matrix and Fourier transformed. Receiver and transmit gains were used for correction of raw signal levels across subjects (Soher et al, 1996). For each voxel, the water reference signal was used to correct shifts in center frequency and time-varying phase modulations, and produced a phased spectrum that contained the three metabolite signals, NAA, Cr, and Cho.

The temporal stability of the amplitude of raw signal acquired on the scanner was analyzed by calculating the average signal for four $30 \times 30$ pixel regions of noise in the periphery of every slice of whole-brain, magnitude, early-echo FSE images from 24 controls scanned over a 16month interval. A linear regression of the noise mean as a function of time yielded a statistically significant decay in the signal level, and was used to produce a temporal correction function for the brain metabolites. The applied correction to account for temporal signal decay was $(14.36+d * 0.001) / 14.359$, where $d$ was time in days.

The dual-echo FSE images were stripped of non-brain tissue with BET (Smith, 2002) and segmented into compartments of gray matter, white matter, and cerebrospinal fluid (CSF). The CSF mask was based on T2 estimates from the dual-echo FSE, and the remaining brain tissue was classified as gray matter or white matter with a nonparametric histogram operator (Lim and Pfefferbaum, 1989; Otsu, 1979). A posterior cortical compartment, predominantly of gray matter, was identified automatically in each subject. This compartment was the intersection of two regions, an outer region and a posterior region. The outer region was identified by successive, concentric, twodimensional erosions of the tissue mask for each slice until $45 \%$ of the total brain mask volume was eroded. The posterior region was created by splitting each slice half way between the anterior and posterior extremes of the tissue mask (Figure 1).

The tissue fraction of spectroscopic voxels in the outer compartment was determined by passing the tissue and fluid masks through a filter identical to the spatial sampling and apodization of the spiral CSI data (Adalsteinsson et al, 2003; Pfefferbaum et al, 1999b). This filter is a radial Hanning window with a 36 pixel diameter in $\left(k_{x}, k_{y}\right)$, multiplied by a 32-pixel wide Hanning window in $k_{z}$. Spectra from voxels in the outer compartment with a tissue fraction of greater than $80 \%$ were averaged, and the contributions of NAA, $\mathrm{Cr}$, and Cho estimated by an integration of $\pm 16 \mathrm{~Hz}$ range centered around the NAA peak, and $\pm 5 \mathrm{~Hz}$ centered around $\mathrm{Cr}$ and Cho. A linear regression of the metabolite values from the control subjects yielded age correction for each of the three metabolites.

Statistical analysis. Group effects were tested with analysis of variance (ANOVA) and follow-up $t$-tests. Bonferroni correction for three comparisons yields a required 


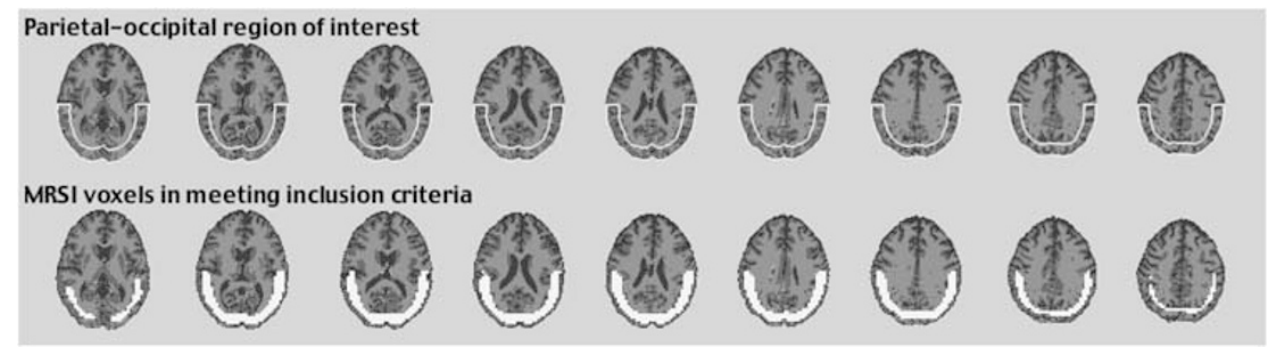

Figure I Representative example (34-year-old man with HIV infection and alcohol dependence) of the parietal-occiptial cortical region of interest used in MRSI metabolite quantification. Top row: Nine axial slices, segmented into compartments of gray matter (dark gray), white matter (light gray), and CSF (black), with the region of interest outlined in white. Bottom row: The same axial slices as in the top row now display the MRSI voxels meeting inclusion criteria (see text for criteria).
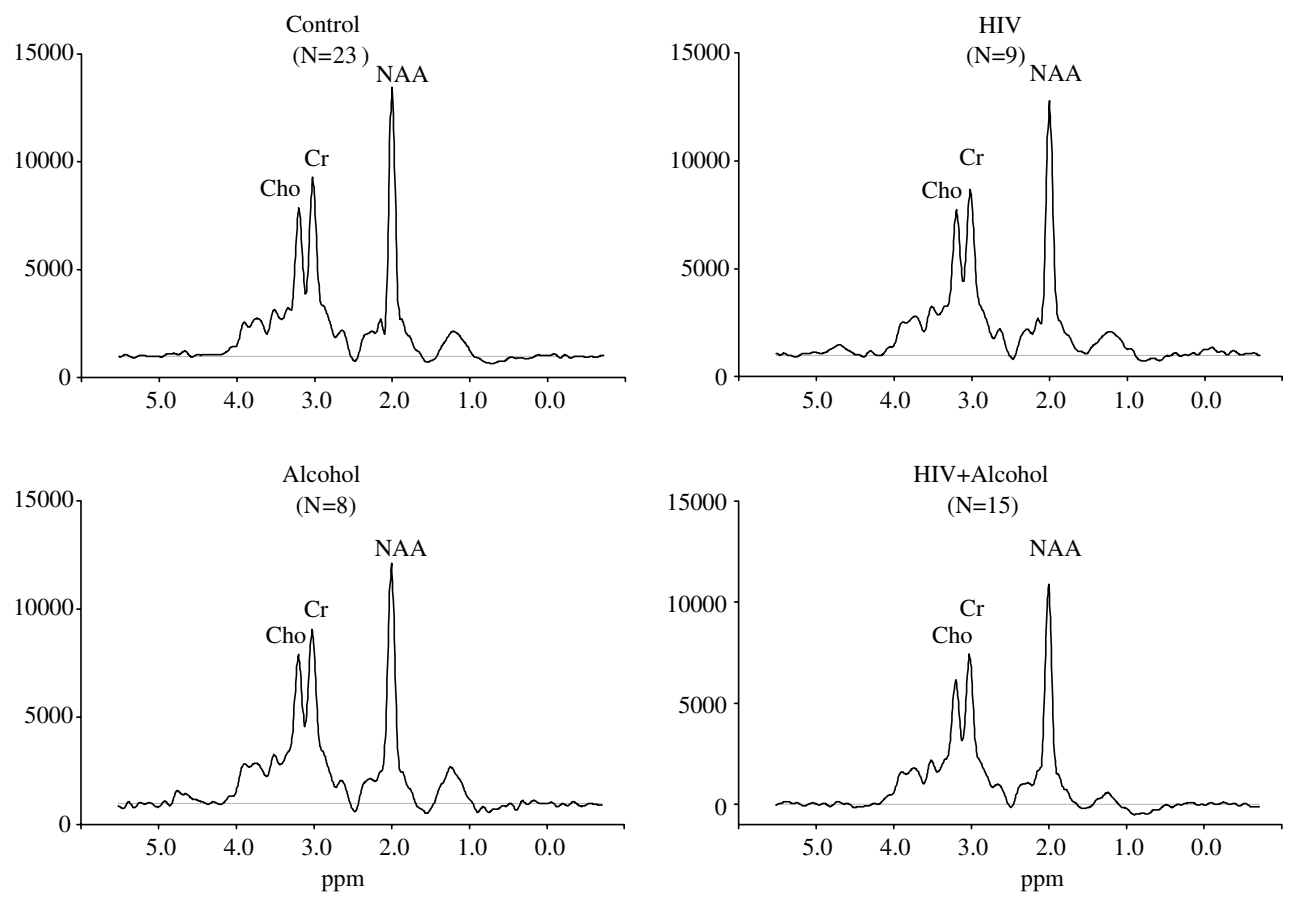

Figure 2 Grand average spectra for each of the four study groups.

alpha $=0.017$, two-tailed. Given that this correction is usually overly conservative, another approach is to apply Bonferroni correction levels to one-tailed predictions. In this case, the corrected $p$-value $=0.034$ for group differences in the predicted direction. The predictions are clear for NAA, which we hypothesize would decline with disease, and choline, which we hypothesize would increase with disease, but is less clear for Cr. Nonetheless, all $p$-values reported are based on two-tailed tests. Relationships between metabolite concentrations and demographic and disease variables were tested with parametric correlations and confirmed with nonparametric tests.

\section{RESULTS}

Within the control group, metabolite values were equivalent in men and women. Further, in the total control group, each of the three measured metabolites showed modest to significant correlations with age as follows: NAA $r=-0.52, p=0.011 ; \operatorname{Cr} r=0.34, p<0.12$; Cho $r=0.29$, $p<0.18$; and NAA/Cr $r=-0.69, p=0.0002$. Thus, prior to conducting group analyses, each subject's metabolite values were adjusted with linear regression to remove the variance associated with age observed in the controls. All of the following analyses used age-corrected standardized $Z$-scores.

\section{Group Differences in Age-Corrected Metabolite Values}

One-way ANOVAs (two-tailed) across the four subject groups calculated for each metabolite yielded differences for NAA $(\mathrm{F}(3,54)=2.790, p<0.05$ and $\mathrm{Cr}(\mathrm{F}(3,54)=2.978$, $p=0.04)$ but not for Cho $(\mathrm{F}(3,54)=1.584, p=0.34)$ or the $\mathrm{NAA} / \mathrm{Cr}$ ratio $(\mathrm{F}(3,54)=1.398, p=0.254)$. Follow-up $t$-tests revealed that the $\mathrm{H}+\mathrm{A}$ group had lower NAA $Z$-scores than either control group $(p<0.025)$ or the HIV group $(p<0.025)$ and lower $\mathrm{Cr} Z$-scores than the control $(p<0.009)$, HIV $(p<0.08)$, and ALC groups $(p<0.035)$ (Figures 2 and 3 ). When the five control women were excluded from the analysis, the overall NAA difference was $p=0.0615$ (two-tailed) and $p=0.0308$ (one-tailed), thus 

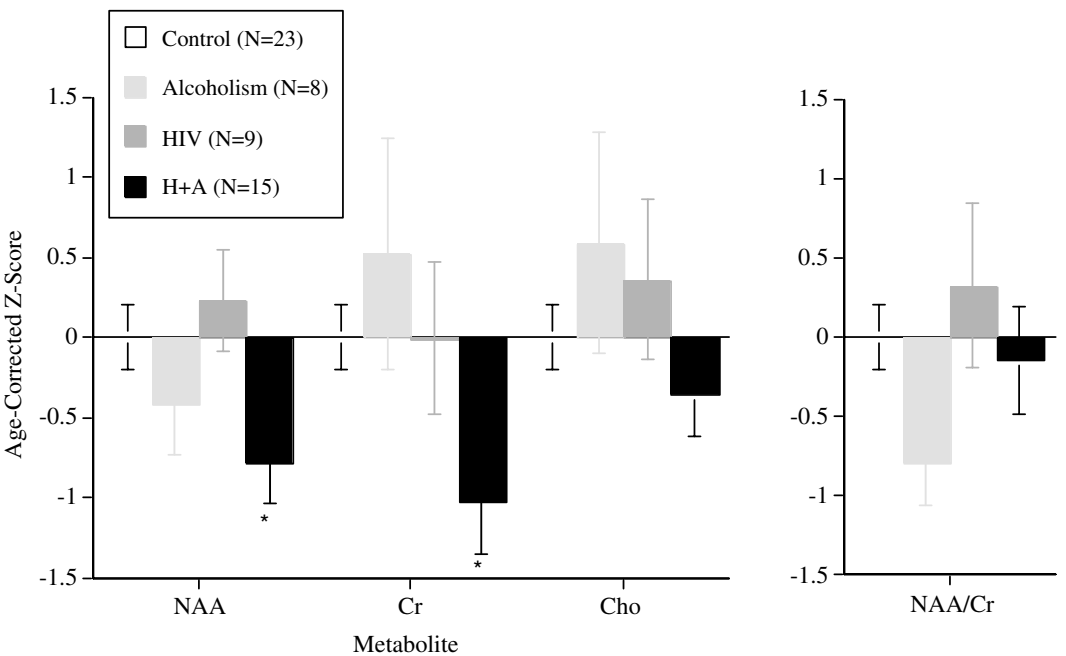

Figure 3 Mean ( \pm SEM bars) of the three metabolites (left) and the NAA/Cr ratio (right) measured in each of the four study groups. The metabolites are absolute values expressed as age-corrected standardized Z-scores. The expected mean values of the controls $=0 \pm$ I SD. Negative values are in the direction of deficit. $* 0.05$.

meeting Bonferroni correction for three comparisons with one-tailed tests, $p=0.034$.

The $\mathrm{H}+\mathrm{A}$ group included 10 men with recent alcohol drinking histories and four with remote drinking histories. To test whether metabolite levels were related to recency of drinking in this group, we tested for group differences with $t$-tests. In no instance did these groups differ from each other: NAA $\mathrm{t}(12)=0.212, p=0.8355 ; \quad \mathrm{Cr} \mathrm{t}(12)=0.34$, $p=0.7401 ;$ Cho $\mathrm{t}(12)=0.193, p=0.8499 ;$ and NAA/Cr $\mathrm{t}(12)=0.015, p=0.9881$. Nonparametric Mann-Whitney tests confirmed these parametric $t$-test results.

It is unlikely that the observed differences in metabolites are attributable to differences in volumes analyzed. The groups did not differ significantly in the number of voxels used in the metabolite measurements $(F(3,54)=2.078$, $p=0.1147)$. The mean $( \pm S E M)$ volume of the region for each group was as follows: controls $=42.7 \pm 5.0 \mathrm{~cm}^{3}$; $\mathrm{HIV}=32.4 \pm 2.6 \mathrm{~cm}^{3} ; \mathrm{H}+\mathrm{A}=31.5 \pm 3.0 \mathrm{~cm}^{3} ;$ and alcoholics $=28.5 \pm 3.0 \mathrm{~cm}^{3}$. Further, the average tissue fraction of the voxels used for spectroscopy quantification was computed for individual subjects, that is, summed and divided by the number of voxels in the average. The average tissue fraction for the voxels used was virtually identical for each group (mean \pm SD for controls $=89.54 \pm 2.24$, $\mathrm{HIV}=89.56 \pm 1.32, \mathrm{H}+\mathrm{A}=89.78 \pm 2.14$, alcoholics $=89.03 \pm$ 2.38; one-way ANOVA $\mathrm{F}(3,54)=0.22, p=0.882$ ).

To test whether metabolite levels were associated with HAART, the two HIV groups were divided into those taking HAART $v s$ those not taking this therapy at the time of scan. $Z$-scores for each metabolite were subjected to two-group by two-therapy ANOVAs. In no case was either the therapy effect or the group-by-therapy interaction significant ( $p$ value ranged between 0.20 and 0.68 ).

\section{Correlations with Age and Disease Variables in the Patient Groups}

None of the three patient groups showed correlations between any age-corrected metabolites or ratio and age, that is, over and above that which would be expected in normal aging. Apart from one notable exception, neither subject variables (lifetime alcohol consumption, days since last drink, or body mass index) nor cognitive test scores (Peabody Picture Vocabulary Test) correlated significantly in the expected direction with any of the metabolite $Z$ scores. The exception involved the alcoholism-only group, for which body mass index was correlated with $Z$-scores of each metabolite was follows: NAA $r=0.85, p<0.012$; Cr $r=0.88, p<0.009$; and Cho $r=0.97, p=0.0003$. The statistical significance of these parametric correlations was confirmed with nonparametric Spearman's correlations.

\section{DISCUSSION}

MR spectroscopic analysis of major proton metabolite peaks revealed that only individuals infected with HIV who were also comorbid for alcoholism were significantly affected, exhibiting a $0.78 \mathrm{SD}$ deficit relative to controls in $\mathrm{NAA}$ and a $1.0 \mathrm{SD}$ deficit in $\mathrm{Cr}$ in the parietal-occipital cortex and subjacent white matter. By contrast, neither HIV infection nor alcoholism alone resulted in any significant posterior cortical metabolite abnormalities. The use of absolute measures revealed deficits in both NAA and $\mathrm{Cr}$ that would have gone undetected if the NAA/Cr ratio were used to examine these patients who were in a relatively mild stage of their disease and pre-dementia. Prior studies, based on ratio measures, have concluded that NAA deficits emerge only in later stages of HIV infection (Meyerhoff et al, 1996) and are typically associated with cognitive impairment (Chang et al, 1999, 2004; Harrison et al, 1998; Meyerhoff et al, 1993; Moller et al, 1999a; Tracey et al, 1996), if at all (von Giesen et al, 2001). Given that NAA and $\mathrm{Cr}$ were both at abnormally low levels in the present study, the NAA deficit would have had to be notably more severe than $\mathrm{Cr}$ to over-ride the concomitant decline in Cr. This possibility was only recently noted as a shortcoming in prior HIV studies (Chang et al, 2002).

In contrast to ratio results for the HIV+alcoholism group, ratios for the alcoholism alone group suggested an 
$\mathrm{NAA} / \mathrm{Cr}$ deficit relative to controls. Traditionally, the metabolite deficit would be attributed to low NAA, assuming no group difference in $\mathrm{Cr}$. To the extent that the data in the present study are generalizable, absolute quantification revealed that this interpretation would be faulty, because the $\mathrm{Cr}$ level was as different from zero in the positive direction as NAA was different in the negative direction, thereby deflating the NAA/Cr ratio. It should be noted that the alcoholics in the present study were abstinent from alcohol for at least several months. As normalization of metabolite levels can occur with extended sobriety (Mann et al, 2001; Martin et al, 1995; Seitz et al, 1999; but see, O'Neill et al, 2001a), the metabolite values of the alcoholic group in the present study may reflect recovery.

The volumetric MRS imaging (MRSI) approach permitted the measurement of neocortical regions not achievable with the large single-voxel approach. The NAA and $\mathrm{Cr}$ deficits observed in parietal-occipital cortex were not related to HAART status and have not been previously reported in HIV-infected individuals before their infection was advanced. The present study provided evidence for significant involvement in posterior cortex at a less severe stage of HIV infection with the stipulation that alcoholism was also a component. Although neither HIV infection nor alcoholism was sufficient to cause the metabolite deficits, each disease apparently carries a liability that puts affected individuals at a heightened risk of neuronal compromise when the diseases are compounded (cf Fein et al, 1998; Meyerhoff, 2001; Pfefferbaum et al, 2002). Further, the neuronal compromise suggested by the observed metabolite patterns for NAA may contribute to the visuospatial processing deficits prominent in alcoholism (for reviews see Fein et al, 1990; OscarBerman, 2000; Sullivan, 2000) and occasionally documented in HIV infection (eg Stern et al, 1996). Interpretation of decreased $\mathrm{Cr}$ is more problematic as it increases with age (Pfefferbaum et al, 1999b) and is in higher concentration in glia than neurons (Barker, 2005; Ernst, 2005). Cr is synthesized in the liver (Ross and Michaelis, 1994), and hepatic pathology could conceivably contribute to decreased brain Cr levels.

Despite the strengths of the current study, it also has limitations. In particular, artifact induced by B0 field inhomogeneity was too severe to permit analysis of frontal lobe and subcortical regions that would otherwise have been desirable to conduct. Further, given current constraints, only long-echo acquisition was possible, thus precluding $\mathrm{mI}$ measurement, increases in which have been shown to occur in the neuroasymptomatic stages (Chang et al, 2004) rather than after the onset of the AIDS dementia complex (Yiannoutsos et al, 2004). Better shimming capabilities, improved signal-to-noise ratios, or the incorporation of $2 \mathrm{D}$ J-resolved spectroscopy to enable the robust acquisition and detection of other metabolites, such as $\mathrm{mI}$ and glutamate (Hurd et al, 2004; Mayer et al, 2004), will be essential to overcome these limitations when volumetric MRSI is employed. Nonetheless, spectroscopic imaging data collected with long-echo times are typically more robust than those collected with short-echo times because of more complete water suppression and reduction of inclusion of nontarget amino acids and macromolecules into the primary metabolite peaks (Spielman et al, 1991).
A large proportion of the HIV subjects had a past history of nonalcohol drug abuse or dependence. Such substance abuse itself can have a significant effect on the major proton metabolites visible with MRS (eg Nordahl et al, 2002) and the potential lingering effects of such history must be recognized and examined in future studies with larger groups that can explicitly target the question of drug abuse comorbidities (O'Neill et al, 2001b).

In conclusion, the use of absolute measures revealed deficits in both NAA and $\mathrm{Cr}$ that would have gone undetected if the traditional $\mathrm{NAA} / \mathrm{Cr}$ ratio were used. Further, alcoholism comorbidity was an essential concomitant for observation of evidence for neuronal compromise (ie low NAA) and high-energy phosphate metabolism (ie low $\mathrm{Cr}$ ) in parietal-occipital cortex in individuals with HIV infection. The exceedingly high prevalence of alcoholism in HIV-infected individuals and the interfering effect of alcohol consumption on HIV therapeutic efforts, both in terms of pharmacological response (Miguez et al, 2003) and therapy compliance (Cerwonka et al, 2000; Samet et al, 2004), underscore the relevance of rigorous study of the compounded diseases.

\section{ACKNOWLEDGEMENTS}

We would like to thank all the research assistants and clinicians in our laboratory for diligence and care in recruitment, scheduling, and data acquisition. Of special note are Andrea Spadoni, BA, for organizing this study as well as Jeffrey Eisen, MBA, Marya Schulte, BA, Carla Raassi, BA, Alex Jack, BA, Stephanie A Sassoon, PhD, Anne O'Reilly, PhD, Julia Buss, RN, Carol Kemper, MD, and Stanley Deresinski, MD. Support for this project came from the National Institute on Alcohol Abuse and Alcoholism (AA12388, AA12999, AA05965).

\section{REFERENCES}

Adalsteinsson E, Langer-Gould A, Homer RJ, Rao A, Sullivan EV, Pfefferbaum A et al (2003). Gray matter NAA deficits in secondary progressive but not relapse remitting multiple sclerosis: quantification with volumetric MR spectroscopic imaging. Am J Neuroradiol 24: 1941-1945.

Adalsteinsson E, StarLack J, Meyer C, Spielman D (1999). Reduced spatial side lobes in chemical-shift imaging. Magn Reson Med 42: 314-323.

American Psychiatric Association (1994). Diagnostic and Statistical Manual of Mental Disorder (DSM-IV). American Psychiatric Association: Washington.

Bagby GJ, Stoltz DA, Zhang P, Kolls JK, Brown J, Bohm Jr RP et al (2003). The effect of chronic binge ethanol consumption on the primary stage of SIV infection in rhesus macaques. Alcohol Clin Exp Res 27: 495-502.

Barker PB (2005). Fundamentals of MR spectroscopy. In: Gillard J, Waldman A, Barker P (eds). Clinical MR Neuroimaging: Diffusion, Perfusion and Spectroscopy. Cambridge University Press: Cambridge. pp 7-26.

Barker PB, Lee RR, McArthur JC (1995). AIDS dementia complex: evaluation with proton MR spectroscopic imaging. Radiology 195: 58-64.

Cerwonka ER, Isbell TR, Hansen CE (2000). Psychosocial factors as predictors of unsafe sexual practices among young adults. AIDS Educ Prev 12: 141-153. 
Chang L, Ernst T, Leonido-Yee M, Witt M, Speck O, Walot I et al (1999). Highly active antiretroviral therapy reverses brain metabolite abnormalities in mild HIV dementia. Neurology 53: 782-789.

Chang L, Ernst T, Witt MD, Ames N, Gaiefsky M, Miller E (2002). Relationships among brain metabolites, cognitive function, and viral loads in antiretroviral-naive HIV patients. Neuroimage 17: 1638-1648.

Chang L, Lee PL, Yiannoutsos CT, Ernst T, Marra CM, Richards T et al (2004). A multicenter in vivo proton-MRS study of HIVassociated dementia and its relationship to age. Neuroimage 23: $1336-1347$

Ernst T (2005). Quantification and analysis in MR spectroscopy. In: Gillard J, Waldman A, Barker P (eds). Clinical MR Neuroimaging: Diffusion, Perfusion and Spectroscopy. Cambridge University Press: Cambridge. pp 27-37.

Ernst T, Chang L (2004). Effect of aging on brain metabolism in antiretroviral-naive HIV patients. AIDS 18(Suppl 1): S61-S67.

Fein G, Bachman L, Fisher S, Davenport L (1990). Cognitive impairments in abstinent alcoholics. West J Med 152: 531-537.

Fein G, Biggins CA, MacKay S (1995). Alcohol abuse and HIV infection have additive effects on frontal cortex function as measured by auditory evoked potential P3a latency. Biol Psychiatry 37: 183-195.

Fein G, Fletcher DJ, Di Sclafani V (1998). Effect of chronic alcohol abuse on the CNS morbidity of HIV disease. Alcohol Clin Exp Res 22: 196S-200S.

Fuller RA, Westmoreland SV, Ratai E, Greco JB, Kim JP, Lentz MR et al (2004). A prospective longitudinal in vivo $1 \mathrm{H} \mathrm{MR}$ spectroscopy study of the SIV/macaque model of neuroAIDS. BMC Neurosci 5: 10.

Green JE, Saveanu RV, Bornstein RA (2004). The effect of previous alcohol abuse on cognitive function in HIV infection. Am J Psychiatry 161: 249-254.

Harrison MJ, Newman SP, Hall-Craggs MA, Fowler CJ, Miller R, Kendall BE et al (1998). Evidence of CNS impairment in HIV infection: clinical, neuropsychological, EEG, and MRI/MRS study. J Neurol Neurosurg Psychiatry 65: 301-307.

Heaton RK, Grant I, Butters N, White DA, Kirson D, Atkinson JH et al (1995). The HNRC 500-neuropsychology of HIV infection at different disease stages. HIV Neurobehavioral Research Center. J Int Neuropsychol Soc 1: 231-251.

Hurd R, Sailasuta N, Srinivasan R, Vigneron DB, Pelletier D, Nelson SJ (2004). Measurement of brain glutamate using TEaveraged PRESS at 3T. Magn Reson Med 51: 435-440.

Karnofsky DA (1949). The clinical evaluation of chemotherapeutic agents in cancer. In: MacLeod CM (ed). Evaluation of Chemotherapeutic Agents. Columbia University Press: New York. pp 191-205.

Kim DH, Adalsteinsson E, Glover GH, Spielman DM (2002). Regularized higher-order in vivo shimming. Magn Reson Med 48: 715-722.

Lee PL, Yiannoutsos CT, Ernst T, Chang L, Marra CM, Jarvik JG et al (2003). A multi-center 1H MRS study of the AIDS dementia complex: validation and preliminary analysis. J Magn Reson Imaging 17: 625-633.

Lefevre F, O’Leary B, Moran M, Mossar M, Yarnold PR, Martin GJ et al (1995). Alcohol consumption among HIV-infected patients. J Gen Intern Med 10: 458-460.

Li BS, Wang H, Gonen O (2003). Metabolite ratios to assumed stable creatine level may confound the quantification of proton brain MR spectroscopy. Magn Reson Imaging 21: 923-928.

Lim KO, Pfefferbaum A (1989). Segmentation of MR brain images into cerebrospinal fluid spaces, white and gray matter. J Comput Assist Tomogr 13: 588-593.

Mann K, Agartz I, Harper C, Shoaf S, Rawlings R, Momenan R et al (2001). Neuroimaging in alcoholism: ethanol and brain damage. Alcohol Clin Exp Res (Suppl) 25: 104-109S.
Martin PR, Gibbs SJ, Nimmerrichter AA, Riddle WR, Welch LW, Willcott MR (1995). Brain proton magnetic resonance spectroscopy studies in recently abstinent alcoholics. Alcohol Clin Exp Res 19: 1078-1082.

Mayer D, Kim D-H, Adalsteinsson E, Spielman DM (2004). Fast CT-PRESS based spiral CSI at 3T. Paper presented at: 12th Annual Meeting of the ISMRM (Kyoto, Japan)..

Meyerhoff DJ (2001). Effects of alcohol and HIV infection on the central nervous system. Alcohol Res Health 25: 288-298.

Meyerhoff DJ, Mackay S, Bachman L, Poole N, Dillon WP, Weiner MW et al (1993). Reduced brain $\mathrm{N}$-acetylaspartate suggests neuronal loss in cognitively impaired human immunodeficiency virus seropositive individuals - in vivo $\mathrm{H}-1$ magnetic resonance spectroscopic imaging. Neurology 43: 509-515.

Meyerhoff DJ, Weiner MW, Fein G (1996). Deep gray matter structures in HIV infection: a proton MR spectroscopic study. Am J Neuroradiol 17: 973-978.

Miguez MJ, Shor-Posner G, Morales G, Rodriguez A, Burbano X (2003). HIV treatment in drug abusers: impact of alcohol use. Addict Biol 8: 33-37.

Moller HE, Vermathen P, Lentschig MG, Schuierer G, Schwarz S, Wiedermann D et al (1999a). Metabolic characterization of AIDS dementia complex by spectroscopic imaging. J Magn Reson Imaging 9: 10-18.

Moller HE, Vermathen P, Lentschig MG, Schuierer G, Schwarz S, Wiedermann D et al (1999b). Metabolic characterization of AIDS dementia complex by spectroscopic imaging. J Magn Reson Imaging 9: 10-18.

Nordahl TE, Salo R, Possin K, Gibson R, Flynn NM, Leamon M et al (2002). Low $N$-acetyl-aspartate and high choline in the anterior cingulum of recently abstinent methamphetamine dependent subjects: a proton MRS study. Psychiatry Res 116: 43-52.

O'Neill J, Cardenas VA, Meyerhoff DJ (2001a). Effects of abstinence on the brain: quantitative magnetic resonance imaging and magnetic resonance spectroscopic imaging in chronic alcohol abuse. Alcohol Clin Exp Res 25: 1673-1682.

O’Neill J, Cardenas VA, Meyerhoff DJ (2001b). Separate and interactive effects of cocaine and alcohol dependence on brain structures and metabolites: quantitative MRI and proton MR spectroscopic imaging. Addict Biol 6: 347-361.

Oscar-Berman M (2000). Neuropsychological vulnerabilities in chronic alcoholism. In: Noronha A, Eckardt M, Warren K (eds). Review of NIAAA's Neuroscience and Behavioral Research Portfolio, NIAAA Research Monograph No. 34, National Institutes of Health: Bethesda, MD. pp 437-472.

Otsu N (1979). A threshold selection method from gray-level histograms. IEEE Trans Syst Man Cybernet 9: 63-66.

Pfefferbaum A, Adalsteinsson E, Spielman D, Sullivan EV, Lim KO (1999a). In vivo brain concentrations of $N$-acetyl compounds, creatine and choline in Alzheimer's disease. Arch Gen Psychiatry 56: $185-192$.

Pfefferbaum A, Adalsteinsson E, Spielman D, Sullivan EV, Lim KO (1999b). In vivo spectroscopic quantification of the $N$-acetyl moiety, creatine and choline from large volumes of gray and white matter: effects of normal aging. Magn Reson Med 41: 276-284.

Pfefferbaum A, Rosenbloom M, Sullivan E (2002). Alcoholism and AIDS: MR imaging approaches for detecting interaction neuropathology. Alcohol Clin Exp Res 26: 1031-1046.

Ross B, Michaelis T (1994). Clinical applications of magnetic resonance spectroscopy. Magn Reson Q 10: 191-247.

Samet JH, Horton NJ, Meli S, Freedberg KA, Palepu A (2004). Alcohol consumption and antiretroviral adherence among HIVinfected persons with alcohol problems. Alcohol Clin Exp Res 28: 572-577.

Seitz D, Widmann U, Seeger U, Nagele T, Klose U, Mann K et al (1999). Localized proton magnetic resonance spectroscopy of the 
cerebellum in detoxifying alcoholics. Alcohol Clin Exp Res 23: $158-163$.

Smith S (2002). Fast robust automated brain extraction. Hum Brain Mapp 17: 143-155.

Soher BJ, van Zijl PCM, Duyn JH, Barker PB (1996). Quantitative proton MR spectroscopic imaging of the human brain. Magn Reson Med 35: 356-363.

Spielman D, Pauly J, Macovski A, Enzmann D (1991). Spectroscopic imaging with multi-dimensional pulses for excitation: SIMPLE. Magn Reson Med 19: 67-84.

Stern RA, Silva SG, Chaisson N, Evans DL (1996). Influence of cognitive reserve on neuropsychological functioning in asymptomatic human immunodeficiency virus-1 infection. Arch Neurol 53: $148-153$.

Sullivan EV (2000). Human brain vulnerability to alcoholism: evidence from neuroimaging studies. In: Noronha A, Eckardt M, Warren K (eds). Review of NIAAA's Neuroscience and Behavioral Research Portfolio, NIAAA Research Monograph No. 34 National Institutes of Health: Bethesda, MD. pp 473-508.

Sullivan EV (2003). Compromised pontocerebellar and cerebellothalamocortical systems: speculations on their contributions to cognitive and motor impairment in nonamnesic alcoholism. Alcohol Clin Exp Res 27: 1409-1419.

Tracey I, Carr CA, Guimaraes AR, Worth JL, Navia BA, Gonzalez RG (1996). Brain choline-containing compounds are elevated in HIV-positive patients before the onset of AIDS dementia complex: a proton magnetic resonance spectroscopic study. Neurology 46: 783-788.

Viondury J, Meyerhoff DJ, Cozzone PJ, Weiner MW (1994). What might be the impact on neurology of the analysis of brain metabolism by in vivo magnetic resonance spectroscopy? J Neurol 241: 354-371.

von Giesen HJ, Wittsack HJ, Wenserski F, Koller H, Hefter H, Arendt G (2001). Basal ganglia metabolite abnormalities in minor motor disorders associated with human immunodeficiency virus type 1. Arch Neurol 58: 1281-1286.

Wang Y, Watson RR (1995). Is alcohol consumption a cofactor in the development of acquired immunodeficiency syndrome? Alcohol 12: 105-109.

Yiannoutsos CT, Ernst T, Chang L, Lee PL, Richards T, Marra CM et al (2004). Regional patterns of brain metabolites in AIDS dementia complex. Neuroimage 23: 928-935. 